Article

\title{
Unveiling the Different Chemical Reactivity of Diphenyl Nitrilimine and Phenyl Nitrile Oxide in [3+2] Cycloaddition Reactions with (R)-Carvone through the Molecular Electron Density Theory
}

\author{
Mar Ríos-Gutiérrez ${ }^{1,2, *} \mathbb{0}$, Luis R. Domingo ${ }^{1}\left(\mathbb{D}, \mathrm{M}^{\prime}\right.$ hamed Esseffar $^{3}$, Ali Oubella ${ }^{3}$ and \\ My Youssef Ait Itto ${ }^{3}$ (i) \\ 1 Department of Organic Chemistry, University of Valencia, Dr. Moliner 50, Burjassot, E-46100 Valencia, Spain; \\ domingo@utopia.uv.es \\ 2 Department of Chemistry and Chemical Biology, McMaster University, 1280 Main Street West, Hamilton, \\ Ontario L8S 4L8, Canada \\ 3 Laboratoire de Synthèse Organique et Physico-Chimie Moléculaire, Département de Chimie, \\ Faculté des Sciences, Semlalia, B.P 2390, Marrakech 40001, Morocco; esseffar@uca.ac.ma (M.E.); \\ oubellaali1@gmail.com (A.O.); aititto@uca.ac.ma (M.Y.A.I.) \\ * Correspondence: rios@utopia.uv.es
}

Academic Editor: Jan M.L. (Gershom) Martin

Received: 1 February 2020; Accepted: 23 February 2020; Published: 28 February 2020

check for updates

\begin{abstract}
The [3+2] cycloaddition (32CA) reactions of diphenyl nitrilimine and phenyl nitrile oxide with (R)-carvone have been studied within the Molecular Electron Density Theory (MEDT). Electron localisation function (ELF) analysis of these three-atom-components (TACs) permits its characterisation as carbenoid and zwitterionic TACs, thus having a different reactivity. The analysis of the conceptual Density Functional Theory (DFT) indices accounts for the very low polar character of these 32CA reactions, while analysis of the DFT energies accounts for the opposite chemoselectivity experimentally observed. Topological analysis of the ELF along the single bond formation makes it possible to characterise the mechanisms of these 32CA reactions as $c b$ - and $z w$-type. The present MEDT study supports the proposed classification of 32CA reactions into $p d r-, p m r-, c b$ - and $z w-t y p e$, thus asserting MEDT as the theory able to explain chemical reactivity in Organic Chemistry.
\end{abstract}

Keywords: [3+2] cycloadditions; nitrilimines; nitrile oxides; chemoselectivity; molecular electron density theory; molecular mechanisms

\section{Introduction}

Five membered heterocyclic compounds, particularly those having the pyrazole and isoxazole frameworks, are components of a diverse array of compounds with a broad spectrum of bioactivities such as analgesic, [1-3] anti-inflammatory [3-5], antibacterial [3,6,7], antifungal [3,8,9], antitumoral [3,10,11] and antiviral $[3,12,13]$ activities.

Among the synthetic routes most often employed, the [3+2] cycloaddition (32CA) reaction of the corresponding three-atom-component (TAC) with an appropriate ethylene derivative is the main approach to access these valuable skeletons, because of its simplicity, efficiency and high selectivity $[10,14,15]$.

Very recently, Ait Itto et al. reported the 32CA reactions of (R)-carvone 1 with diaryl nitrilimines (NIs) $\mathbf{2 a - d}$ and arylnitrile oxides (NOs) $\mathbf{4 a - d}$ in dichloromethane (DCM), yielding pyrazoles $\mathbf{3 a}-\mathbf{d}$ and isoxazoles 5a-r, respectively (see Scheme 1) [16]. These 32CA reactions presented total regioand chemoselectivity, resulting in a mixture of a pair of diastereoisomers resulting from the attack of 
these TACs by the two faces of the two $\mathrm{C}-\mathrm{C}$ double bonds of (R)-carvone 1. Interestingly, these 32CA reactions showed contrary chemoselectivity depending on the nature of the TAC; thus, diaryl NIs $\mathbf{2 a - d}$ preferred the attack on the $\alpha, \beta$-conjugated $\mathrm{C}-\mathrm{C}$ double bond of (R)-carvone 1, while aryl-NOs $4 \mathbf{a}-\mathbf{d}$ preferred the attack on the isopropenyl C-C double bond (see Scheme 1) [16].<smiles>CC1=CC[C@@H](C2(C)CC([Al])NO2)CC1=O</smiles>

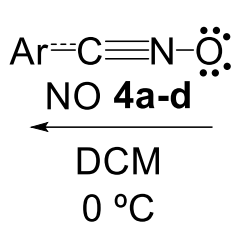

5a-d<smiles>C=C(C)[C@@H]1CC=C(C)C(O)C1</smiles>

1

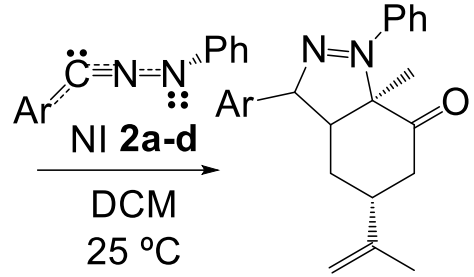

3a-d

$$
\begin{aligned}
& \text { a } \mathrm{Ar}=\mathrm{C}_{6} \mathrm{H}_{5} \\
& \text { b } \mathrm{Ar}=4-\mathrm{CH}_{3}-\mathrm{C}_{6} \mathrm{H}_{4} \\
& \text { c } \mathrm{Ar}=4-\mathrm{Cl}-\mathrm{C}_{6} \mathrm{H}_{4} \\
& \text { d } \mathrm{Ar}=4-\mathrm{NO}_{2}-\mathrm{C}_{6} \mathrm{H}_{4}
\end{aligned}
$$

Scheme 1. [3+2] cycloaddition (32CA) reactions of (R)-carvone $\mathbf{1}$ with diaryl NIs $\mathbf{2 a - d}$ and aryl-NOs 4a-d.

The study of chemical reactivity is incomplete without the blending of experimental results and theoretical rationalisation. 32CA reactions have been widely studied theoretically. In 2007, Houk proposed the Distortion/Interaction Model (DIM) [17,18], which is analogous to the Activation Strain Model (ASM) proposed in 1999 by Bickelhaupt [19], to explain the reactivity of the twelve simplest TACs in 32CA reactions towards ethylene 6 and acetylene 7. Houk found that the computed B3LYP/6-31G(d) activation enthalpies correlated very nicely with the distortion energies $\Delta \mathrm{E}_{\mathrm{d}} \neq$. However, in spite of this good correlation between the activation enthalpies and the distortion energies $\Delta \mathrm{E}_{\mathrm{d}} \neq$, that energy decomposition analysis was not able to explain the different experimentally observed chemical reactivity of the studied TACs.

Recent advances made in the theoretical understanding of 32CA reactions based on the Molecular Electron Density Theory [20] (MEDT) have allowed establishing a very good correlation between the electronic structure of the simplest TACs and their reactivity towards ethylene 6 [21]. Accordingly, depending on the electronic structure of the simplest TACs, pseudodiradical, pseudoradical, carbenoid and zwitterionic, 32CA reactions have been classified into pdr-type, pmr-type, cb-type and zw-type reactions [21], respectively, in such a manner that while $p d r$-type 32CA reactions can be carried out very easily, zw-type 32CA reactions demand adequate nucleophilic/electrophilic activations to take place [22].

These MEDT studies permitted the classification of the simplest NI 8 as a carbenoid TAC [23] and the simplest NO 9 as a zwitterionic TAC [24] (see Chart 1), also characterising a different reactivity for both of them. Thus, while carbenoid NI 8 reacts through the nucleophilic attack on the $\beta$-conjugated position of electrophilic ethylene in a cb-type 32CA reaction [23], the low electrophilic and nucleophilic character of zwitterionic NO 9 makes it participate in zw-type 32CA reactions with low polar character and high activation energies [24]. Consequently, it is expected that the aryl-substituted NIs $\mathbf{2 a - d}$ and NOs 4a-d given in Scheme 1 would experience a different reactivity towards the $\alpha, \beta$-conjugated and the isopropenyl $\mathrm{C}-\mathrm{C}$ double bonds present in (R)-carvone $\mathbf{1}$. 
<smiles>[CH]=[N+]=N[CH2-]</smiles>

NI 8<smiles></smiles>

NO 9

carbenoid structure zwitterionic structure

Chart 1. Electron Localisation Function (ELF)-based carbenoid and zwitterionic Lewis-like structures of the simplest NI 8 and NO 9 Three-Atom-Components (TACs).

Thus, in view of the different chemical reactivity experienced by diaryl-NIs $\mathbf{2 a - d}$ and aryl-NOs 4a-d towards the two different $\mathrm{C}-\mathrm{C}$ double bonds of (R)-carvone 1, experimentally studied by Ait Itto et al. [16], an MEDT study of the 32CA reactions of diphenyl NI 2a and with phenyl-NO 4a towards (R)-carvone 1 is herein carried out in order to shed light on the experimental outcomes, i.e., the opposite chemoselectivity of the 32CA reactions of these TACs with (R)-carvone 1.

\section{Results and Discussion}

2.1. Topological Analysis of the Electron Localisation Function (ELF) and Natural Population Analysis (NPA) of Diphenyl-NI 2a, Phenyl-NO 4a and (R)-Carvone $\mathbf{1}$

In order to characterise the electronic structure of diphenyl-NI $\mathbf{2 a}$ and phenyl NO $4 \mathbf{a}$ and, thus, to establish their reactivity in 32CA reactions [21], a topological analysis of the ELF [25] of these TACs was first performed; the electronic structure of (R)-carvone $\mathbf{1}$ is also analysed. ELF localisation domains, ELF basin attractor positions together with the valence basin populations, as well as the proposed ELF-based Lewis-like structures together with the natural atomic charges, are shown in Figure 1. Lewis-like structures come from the adaption of ELF basin populations to fit the Lewis bonding model. Thus, populations below 1e have been associated with radical or pseudoradical centres, populations between 1e and 2e with a single bond or a lone pair, between $3 e$ and 4e with double bonds or two lone pairs, while more than $5 \mathrm{e}$ are associated with triple bonds or three lone pairs.

Topological analysis of the ELF of diphenyl NI 2a shows the presence of one monosynaptic basin $\mathrm{V}(\mathrm{C} 1)$ integrating $1.44 \mathrm{e}$, two disynaptic basins, $\mathrm{V}(\mathrm{C} 1, \mathrm{~N} 2)$ and $\mathrm{V}^{\prime}(\mathrm{C} 1, \mathrm{~N} 2)$, integrating $2.56 \mathrm{e}$ and $2.19 \mathrm{e}$, one $\mathrm{V}(\mathrm{N} 2, \mathrm{~N} 3)$ disynaptic basin integrating $2.15 \mathrm{e}$, and one $\mathrm{V}(\mathrm{N} 3)$ monosynaptic basin integrating 3.32e. Within the context of ELF, monosynaptic basins, labelled $\mathrm{V}(\mathrm{A})$, are associated with non-bonding electron density regions, while disynaptic basins, labelled $\mathrm{V}(\mathrm{A}, \mathrm{B})$, connect the core of two nuclei $\mathrm{A}$ and $\mathrm{B}$ and, thus, correspond to a bonding region between nuclei A and B [26]. This description, together with the ELF valence basin populations, allows relating the monosynaptic basin $\mathrm{V}(\mathrm{C} 1)$ with a depopulated $\mathrm{C} 1$ carbenoid centre, the two disynaptic basins, $\mathrm{V}(\mathrm{C} 1, \mathrm{~N} 2)$ and $\mathrm{V}^{\prime}(\mathrm{C} 1, \mathrm{~N} 2)$, with a populated $\mathrm{C} 1-\mathrm{N} 2$ double bond, integrating a total of $4.75 \mathrm{e}$, the $\mathrm{V}(\mathrm{N} 2, \mathrm{~N} 3)$ disynaptic basin with a slightly overpopulated N2-N3 single bond, and the V(N3) monosynaptic basin with an overpopulated N3 lone pair. The non-planar geometry of diphenyl NI 2a, together with the presence of the carbenoid centre, suggest that this linear TAC has an allenic structure [23]. Consequently, the topological analysis of the ELF of diphenyl NI 2a indicated that, just as the simplest NI 8 [23], this TAC has a carbenoid structure participating in cb-type 32CA reactions.

Topological analysis of the ELF of phenyl NO 4a shows the presence of two disynaptic basins, $\mathrm{V}(\mathrm{C} 1, \mathrm{~N} 2)$ and $\mathrm{V}^{\prime}(\mathrm{C} 1, \mathrm{~N} 2)$, integrating $2.78 \mathrm{e}$ and $3.16 \mathrm{e}$, one $\mathrm{V}(\mathrm{N} 2, \mathrm{O} 3)$ disynaptic basin integrating 1.61 $\mathrm{e}$, and two monosynaptic basins, $\mathrm{V}(\mathrm{O} 3)$ and $\mathrm{V}^{\prime}(\mathrm{O} 3)$ integrating $2.60 \mathrm{e}$ and $3.05 \mathrm{e}$. The sinapticity of the valence basins, together with the ELF valence basin populations, allows relating the $\mathrm{V}(\mathrm{C} 1, \mathrm{~N} 2)$ and $\mathrm{V}^{\prime}(\mathrm{C} 1, \mathrm{~N} 2)$ disynaptic basins, which integrate a total of $5.94 \mathrm{e}$, with a $\mathrm{C}-\mathrm{N}$ triple bond, the $\mathrm{V}(\mathrm{N} 2, \mathrm{O} 3)$ disynaptic basin with a depopulated $\mathrm{N} 2-\mathrm{O} 3$ single bond, and the two $\mathrm{V}(\mathrm{O} 3)$ and $\mathrm{V}^{\prime}(\mathrm{O} 3)$ monosynaptic basins with two overpopulated $\mathrm{O} 3$ lone pairs. The linear geometry of phenyl NO 9, together with this ELF analysis suggest that this TAC has a propargylic structure. Consequently, the topological analysis of the ELF of phenyl NO 4a indicates that this TAC has a zwitterionic structure [24] participating 
in zw-type 32CA reactions, just as the simplest NO 9, thus presenting a different reactivity to that of carbenoid diphenyl NI 2a.

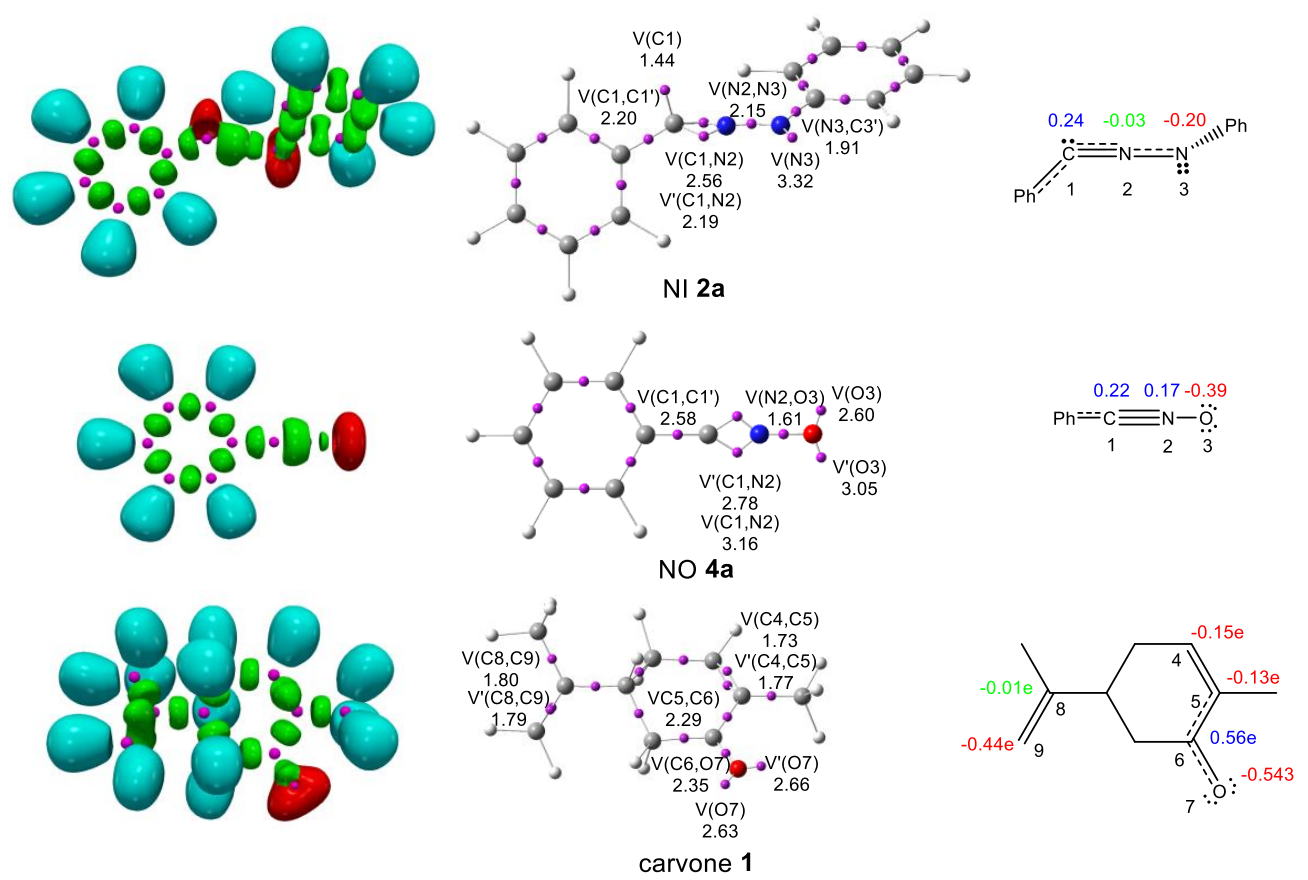

Figure 1. B3LYP/6-31G(d) ELF localisation domains, represented at an isosurface value of ELF $=0.75$, ELF basin attractor positions, together with the valence basin populations, and the proposed ELF-based Lewis-like structures, together with the natural atomic charges, of diphenyl-NI 2a, phenyl-NO 4a and (R)-carvone 1. For ELF localisation domains, protonated domains are coloured in turquoise, disynaptic domains in green, monosynaptic domains in red, and core domains in purple. For the geometries, the standard colour code for chemical elements is used, while the attractors of ELF basins are coloured in purple. For charges, negative charges are coloured in red, positive charges in blue and negligible charges in green. ELF valence basin populations and natural atomic charges are given in average number of electrons, e.

Finally, topological analysis of the ELF of (R)-carvone 1 shows the presence of two disynaptic basins, $\mathrm{V}(\mathrm{C} 4, \mathrm{C} 5)$ and $\mathrm{V}^{\prime}(\mathrm{C} 4, \mathrm{C} 5)$, integrating $1.77 \mathrm{e}$ and $1.76 \mathrm{e}$, one $\mathrm{V}(\mathrm{C} 5, \mathrm{C} 6)$ disynaptic basin integrating $2.29 \mathrm{e}$, one $\mathrm{V}(\mathrm{C} 6, \mathrm{O} 7)$ disynaptic basin integrating $2.35 \mathrm{e}$, and two monosynaptic basins, $\mathrm{V}(\mathrm{O} 7)$ and $\mathrm{V}^{\prime}(\mathrm{O} 7)$, integrating $2.66 \mathrm{e}$ and $2.63 \mathrm{e}$. On the other hand, (R)-carvone 1 also shows the presence of two disynaptic basins, $\mathrm{V}(\mathrm{C} 8, \mathrm{C} 9)$ and $\mathrm{V}^{\prime}(\mathrm{C} 8, \mathrm{C} 9)$, integrating 1.80 e and 1.79 e. The sinapticity of the valence basins, together with the ELF valence basin populations, allows relating the $V(C 4, C 5)$ and $\mathrm{V}^{\prime}(\mathrm{C} 4, \mathrm{C} 5)$ disynaptic basins with a $\mathrm{C} 4-\mathrm{C} 5$ double bond, integrating a total of $3.53 \mathrm{e}$, the $\mathrm{V}(\mathrm{C} 5, \mathrm{C} 6)$ and $\mathrm{V}(\mathrm{C} 6, \mathrm{O} 7)$ disynaptic basins to a populated $\mathrm{C} 5-\mathrm{C} 6$ and $\mathrm{C} 6-\mathrm{O} 7$ single bonds, and the two $\mathrm{V}(\mathrm{O} 7)$ and $\mathrm{V}^{\prime}(\mathrm{O} 7)$ monosynaptic basins with two overpopulated O7 lone pairs. Finally, the two V(C8,C9) and $\mathrm{V}^{\prime}(\mathrm{C} 8, \mathrm{C} 9)$ disynaptic basins could be related to a C8-C9 double bond.

Once the bonding patterns of the reagents were established, the charge distribution was analysed through natural population analysis (NPA). NPA of diphenyl NI 2a and phenyl NO 4a shows polarisation of the electron density of these TACs towards the terminal N3 nitrogen and O3 oxygen, respectively. Note that this polarisation is larger at phenyl NO $4 \mathbf{a}$ as a consequence of the more electronegative character of the oxygen atom that the nitrogen one (see Figure 1). It is interesting to remark that the charge distribution of phenyl NO $4 \mathbf{a}$, which is classified as a zwitterionic TAC, is not a consequence of the set of resonance Lewis structures, as proposed [27], but of the different nature of the three nuclei of this TAC [21]. 


\subsection{Analysis of the Conceptual Density Functional (CDFT) Reactivity Indices of the Reagents}

Numerous studies devoted to Diels-Alder and 32CA reactions have shown that the analysis of the reactivity indices defined within CDFT $[28,29]$ is a powerful tool to predict and understand the reactivity in polar and ionic organic reactions. Thus, in order to predict the reactivity of diphenyl NI 2a, phenyl NO 4a and (R)-carvone 1 in the corresponding 32CA reactions, the global CDFT reactivity indices, i.e., the electronic chemical potential, $\mu$, the chemical hardness, $\eta$, the electrophilicity, $\omega$, and the nucleophilicity, $N$, at the ground state of the reagents, were computed and analysed (see Table 1).

Table 1. B3LYP/6-31G(d) global electronic chemical potential, $\mu$, chemical hardness, $\eta$, electrophilicity, $\omega$, and nucleophilicity, $N$, in eV, of NIs $2 a, 8, N O s$ a, 9 and (R)-carvone 1.

\begin{tabular}{ccccc}
\hline & $\boldsymbol{\mu}$ & $\boldsymbol{\eta}$ & $\boldsymbol{\omega}$ & $\boldsymbol{N}$ \\
\hline diphenyl NI 2a & -3.36 & 3.78 & 1.50 & 3.87 \\
phenyl NO 4a & -3.83 & 5.02 & 1.46 & 2.78 \\
(R)-carvone 1 & -3.84 & 5.23 & 1.41 & 2.67 \\
simplest NI 8 & -3.55 & 5.87 & 1.07 & 2.64 \\
simplest NO 9 & -3.40 & 7.94 & 0.73 & 1.75 \\
\hline
\end{tabular}

The electronic chemical potential $\mu[30,31]$ of diphenyl NI $\mathbf{2 a}, \mu=-3.36 \mathrm{eV}$, is only slightly higher than that of (R)-carvone1, $\mu=-3.84 \mathrm{eV}$; consequently, diphenyl NI $2 \mathrm{a}$ will not be very prone to transfer electron density towards (R)-carvone 1 , and the corresponding 32CA reaction is expected to have a low polar character. On the order hand, the electronic chemical potential $\mu$ of the phenyl NO $4 a, \mu=-3.83$ $\mathrm{eV}$, is almost identical to that of $(\mathrm{R})$-carvone 1, indicating that the corresponding 32CA reaction will have a clear non-polar character.

The chemical hardness $\eta$ indices of the simplest NI 8 and NO 9 are 5.87 and $7.94 \mathrm{eV}$. The substitution of the hydrogens by phenyl groups decreases by ca. $2 \mathrm{eV}$ the chemical hardness $\eta$ [30] of both experimental TACs diphenyl NI 2a and phenyl NO 4a (see Table 1), indicating that the substitution makes them more prone to the bonding changes, thus decreasing the activation energies. The chemical hardness $\eta$ of diphenyl NI $\mathbf{2 a}, 3.78 \mathrm{eV}$, is much lower than that of (R)-carvone 1, $5.23 \mathrm{eV}$, indicating that along the reaction path, the bonding changes at the NI framework will take place more easily than those at the ethylene one. Conversely, the chemical hardness $\eta$ of phenyl NO 4a, $5.02 \mathrm{eV}$, is similar to that of (R)-carvone 1, indicating a similar trend for bonding changes in both structures along the reaction path.

The electrophilicity $\omega$ index [32] of the simplest NI 8 and the simplest NO 9 is 1.07 and $0.73 \mathrm{eV}$, respectively, being classified as strong and moderate electrophiles within the electrophilicity scale [29]. On the other hand, the nucleophilicity $N$ index [33] of these TACs is 2.64 (8) and 1.75 (9) eV. Thus, while the simplest NI 8 is classified as a moderate nucleophile, the simplest NO 9 is classified as a marginal nucleophile within the nucleophilicity scale [29]. The low electrophilicity $\omega$ and nucleophilicity $N$ indices of the simplest NO 9 indicate that the corresponding zw-type 32CA reaction will have a non-polar character, in agreement with the analysis of the electronic chemical potentials, and high activation energy [24].

On the other hand, diphenyl NI 2a and phenyl NO 4a have similar electrophilicity indices, 1.50 and $1.46 \mathrm{eV}$, respectively, both being classified as strong electrophiles, while their nucleophilicity $N$ indices are 3.87 (2a) and 2.78 (4a) eV. Thus, while diphenyl NI $\mathbf{2 a}$ is classified as a strong nucleophile, phenyl NO 2a is classified as a moderate nucleophile. Consequently, the inclusion of the phenyl group in the simplest TACs NI 8 and NO 9 increases their electrophilic and nucleophilic character.

The electrophilicity $\omega$ and nucleophilicity $N$ indices of (R)-carvone 1 are $1.41 \mathrm{eV}$ and $2.67 \mathrm{eV}$, respectively, is classified as a moderate electrophile and a moderate nucleophile.

Analysis of the global CDFT indices indicates that although diphenyl NI 2a is classified as a strong nucleophile, the low electrophilic character of (R)-carvone 1 provides the corresponding 32CA reaction 
with a very low polar character. On the other hand, the low electrophilic and nucleophilic character of phenyl NO 4a does not permit its participation in polar processes.

\subsection{Study of the Reaction Paths Associated with the 32CA Reactions of Diphenyl NI 2a and Phenyl NO 4a} with $(R)$-Carvone 1

\subsubsection{Study of the 32CA Reactions of Diphenyl NI 2a with (R)-Carvone 1}

First, the 32CA reaction of diphenyl NI 2a with (R)-carvone 1 was studied. Due to the non-symmetry of the reagents and the presence of two $\mathrm{C}-\mathrm{C}$ double bonds in $(\mathrm{R})$-carvone 1, eight reactive paths are feasible. Only four reaction paths were considered: the attack to the $\mathrm{C} 4-\mathrm{C} 5$ or $\mathrm{C} 8-\mathrm{C} 9$ double bonds of (R)-carvone 1, and the two regioisomeric approach modes of diphenyl NI 2a to these C-C double bonds (see Scheme 2). Facial selectivity was not considered [16]. Analysis of the mentioned reaction paths allowed locating and characterising four TSs and the corresponding pyrazoles, indicating that this 32CA reaction takes place through a one-step mechanism (see Scheme 2). B3LYP/6-311G(d,p) relative enthalpies and Gibbs free energies in DCM are given in Scheme 2. The total and relative energies in the gas phase and in DCM, as well as the thermodynamic data, are given in Tables S4 and S7 in the Supplementary Material.
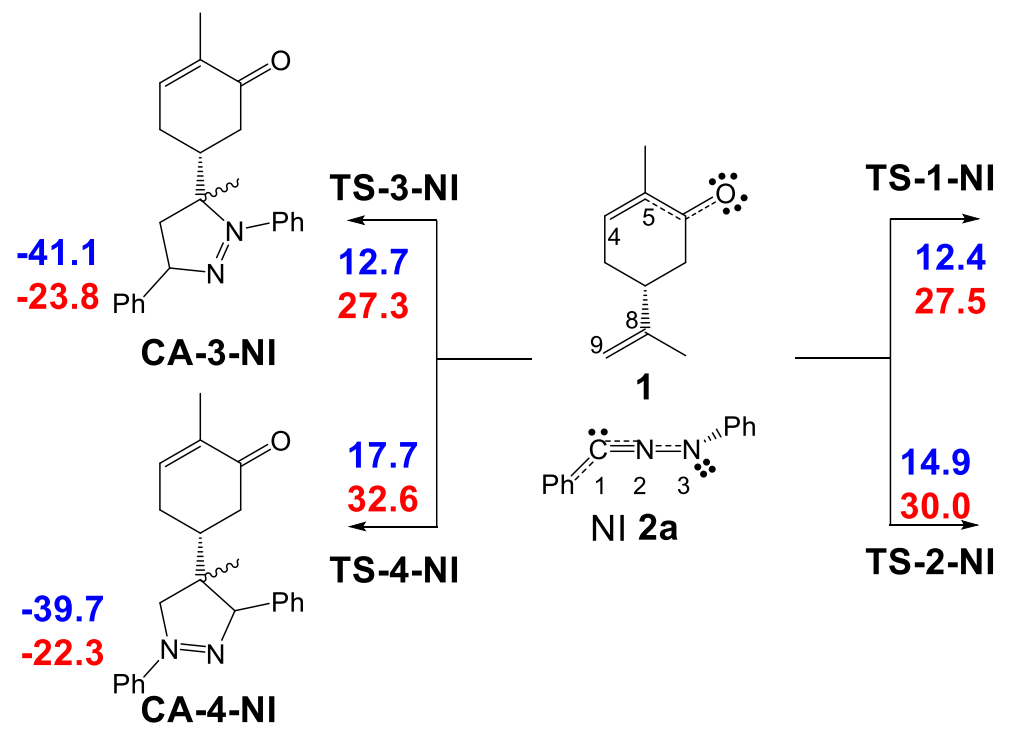
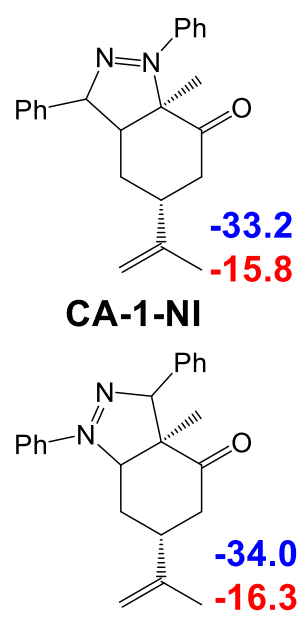

CA-2-NI

Scheme 2. Studied reaction paths associated with the 32CA reaction of diphenyl NI 2a with (R)-carvone 1. B3LYP/6-311G $(\mathrm{d}, \mathrm{p})$ relative enthalpies, in blue, and relative Gibbs free energies, in red, computed at $25^{\circ} \mathrm{C}$ in $\mathrm{DCM}$, are given in $\mathrm{kcal} \cdot \mathrm{moL}^{-1}$. The energy reference is the separated reagents.

The B3LYP/6-311G $(\mathrm{d}, \mathrm{p})$ activation enthalpies associated with the four competitive reaction paths

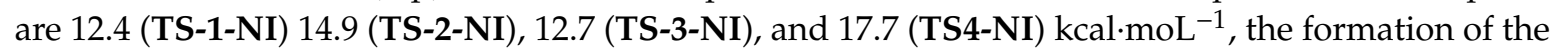
pyrazoles being exothermic by $33-41 \mathrm{kcal} \cdot \mathrm{moL}^{-1}$. Some appealing conclusions can be drawn from these energy results: (i) this 32CA reaction presents an activation enthalpy via TS-1-NI of $12.4 \mathrm{kcal} \cdot \mathrm{moL}^{-1}$. The activation energy associated with the 32CA between the simplest NI 8 and ethylene 6 is 10.5 $\mathrm{kcal} \cdot \mathrm{moL}^{-1}$ (see Table S8 in Supplementary Material); (ii) this 32CA reaction is highly regioselective, as TS-2-NI is $2.5 \mathrm{kcal} \cdot \mathrm{moL}^{-1}$ higher in enthalpy than TS-1-NI; (iii) this 32CA reaction presents a low chemoselectivity as TS-3-NI is only $0.3 \mathrm{kcal} \cdot \mathrm{moL}^{-1}$ higher in enthalpy than TS-1-NI. Note, however, that at the MPWB1K computational level, TS-3-NI is $3.0 \mathrm{kcal} \cdot \mathrm{moL}^{-1}$ higher in enthalpy than TS-1-NI (see Table S1 in Supplementary Material); (iv) the high exothermic character of the four reaction paths makes them irreversible. Consequently, the formation of the most favourable pyrazole CA-1-NI is subject to a kinetic control. 
The B3LYP/6-31G(d) gas phase and in DCM geometries of the four TSs are given in Figure 2. The distances between the interacting $\mathrm{C} 1$ and $\mathrm{Cx}$ and N3 and Cy centres at the gas phase TSs are 2.213

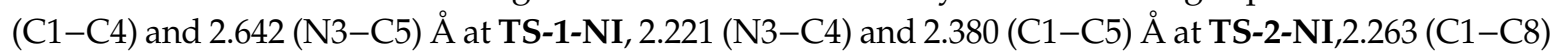

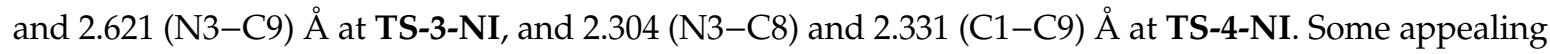
conclusions can be drawn from these geometrical parameters: (i) the more favourable regioisomeric TSs,TS-1-NI and TS-3-NI, are more asynchronous than TS-2-NI and TS-4-NI; (ii) the most favourable TS-1-NI is associated with a two-centre interaction between the most nucleophilic centre of diphenyl NI 1, the carbenoid C1 carbon, and the most electrophilic centre of carvone 3 , the $\beta$-conjugated $\mathrm{C} 4$ carbon (see Section S1 in Supplementary Material); (iii) the C-C and C-N distances associated to the formation of the corresponding single bonds, $>2.2 \AA$, indicating that formation of these single bonds has not started yet at any of the four TSs [21]; and (iv) a comparison of the geometrical parameters obtained at the B3LYP/6-31G(d) level, in the gas phase and in DCM, and those obtained at the B3LYP/6-311G(d,p) level in DCM, shows that there are no significant differences (see Figure 2).
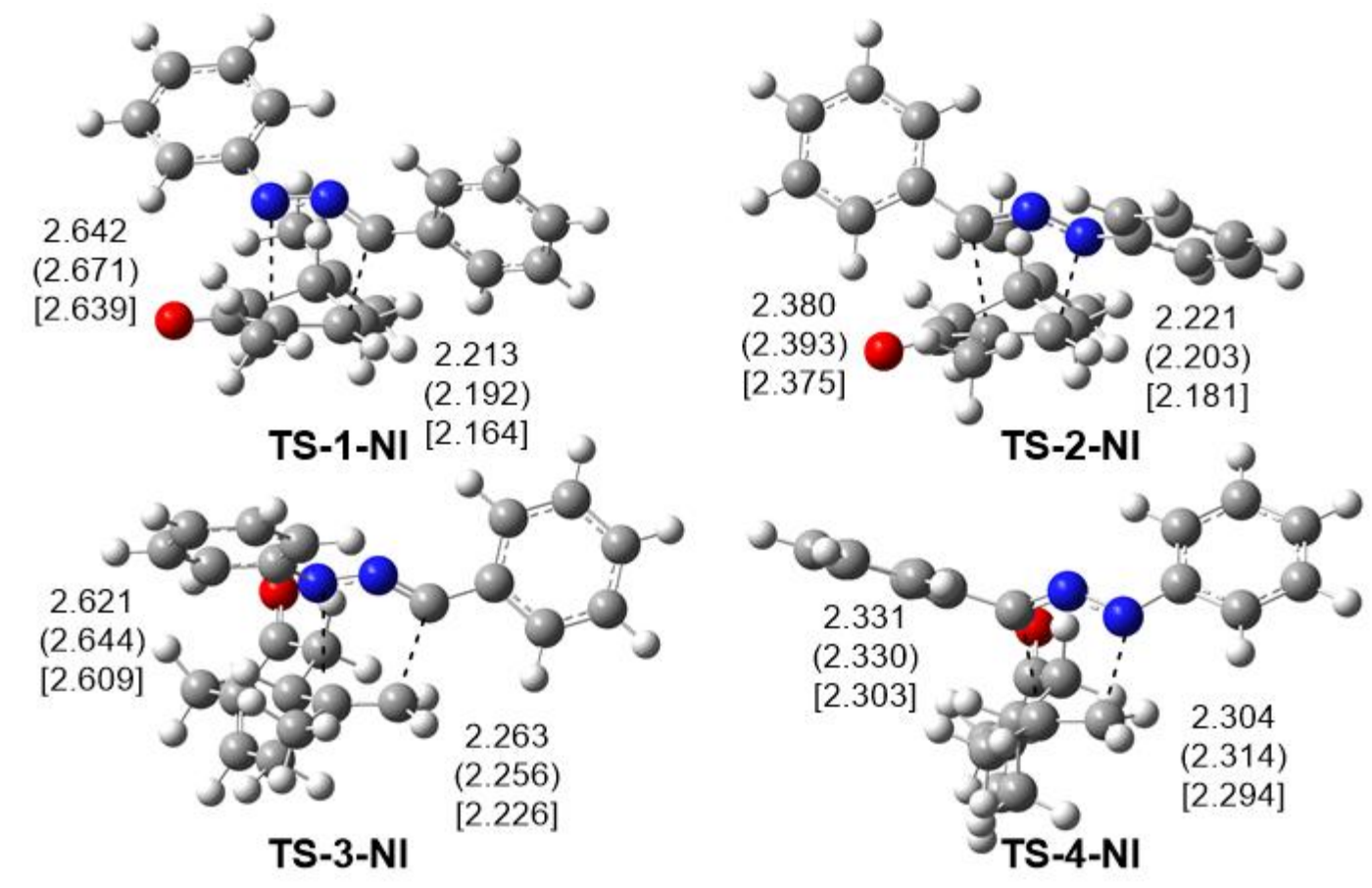

Figure 2. B3LYP/6-31G(d) optimised geometries, in the gas phase and in dichloromethane (DCM), of the transition state structures (TSs) involved in the 32CA reaction of diphenyl NI 2a with (R)-carvone 1. Distances are given in angstroms, $\AA$. Values in DCM are given in parentheses, while the B3LYP/6-311G(d,p) values in DCM are given in brackets.

Finally, in order to evaluate the polar nature of the 32CA reaction of diphenyl NI 2a with (R)-carvone 1, the global electron density transfer (GEDT) [34] at the more favourable regioisomeric TSs was analysed. Reactions with GEDT values of 0.0 e correspond to non-polar processes, while values above 0.2 e correspond to polar processes. The values of GEDT, which fluxes from the diphenyl NI framework to the (R)-carvone 1 at the more favourable regioisomeric TSs are 0.06 e at TS-1-NI and -0.02 e at TS-3-NI. These negligible values indicate that this 32CA reaction has non-polar character as a consequence of the moderate electrophilic character of (R)-carvone 1 , in clear agreement with the analysis of the CDFT indices.

\subsubsection{Study of the 32CA Reactions of Phenyl NO 4a with (R)-Carvone 1}

Just as in the 32CA reaction of diphenyl NI 2a, eight reactive paths are feasible for this 32CA reaction due to the non-symmetry of phenyl NO $4 \mathbf{a}$ and $(\mathrm{R})$-carvone $\mathbf{1}$. Four reaction paths were 
considered: the attack to the $\mathrm{C} 4-\mathrm{C} 5$ or $\mathrm{C} 8-\mathrm{C} 9$ double bonds of (R)-carvone 1 , and the regioisomeric approach modes of phenyl NO 4 a to these $\mathrm{C}-\mathrm{C}$ double bonds (see Scheme 3). Facial selectivity was not considered [16]. Analysis of the stationary points involved in the four reaction paths indicates that this 32CA reaction takes place also through a one-step mechanism. Thus, four TSs and the corresponding isoxazoles were located and characterised (see Scheme 3). B3LYP/6-311G(d,p) relative enthalpies and Gibbs free energies in DCM are given in Scheme 3. The total and relative energies in the gas phase and in DCM and the thermodynamic data are given in Tables S5 and S7 in Supplementary Material.<smiles>CC1=CC[C@@H](C2(C)CC(c3ccccc3)N=N2)CC1=O</smiles><smiles>CC1=CC[C@@H](C2([As](C)N=O)CON=C2c2ccccc2)CC1=O</smiles>

CA-4-NO
TS-3-NO

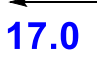

28.7

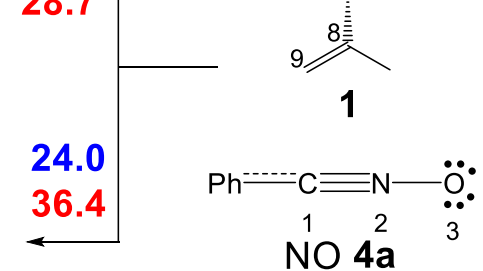

TS-4-NO

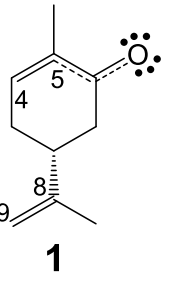

NO $4 a$

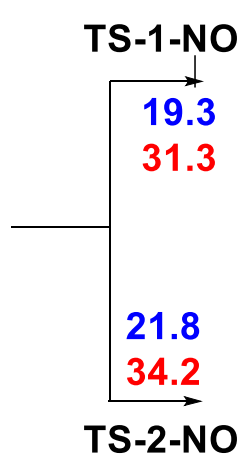

TS-2-NO<smiles>C=C(C)[C@@H]1CC(=O)[C@]2(C)ON=C(c3ccccc3)C2C1</smiles>

CA-1-NO

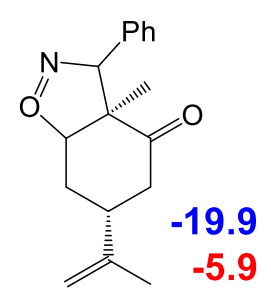

CA-2-NO

Scheme 3. Selected reaction paths associated with the 32CA reaction of phenyl NO 4a with (R)-carvone 1. B3LYP/6-311G $(\mathrm{d}, \mathrm{p})$ relative enthalpies, in blue, and relative Gibbs free energies, in red, computed at $0{ }^{\circ} \mathrm{C}$ in $\mathrm{DCM}$, are given in $\mathrm{kcal} \cdot \mathrm{moL}^{-1}$. The energy reference is the separated reagents.

The B3LYP/6-311G(d,p) activation enthalpies associated with the four competitive reaction paths are 19.3 (TS-1-NO) 21.8 (TS-2-NO), 17.0 (TS-3-NO), and 24.0 (TS4-NO) $\mathrm{kcal} \cdot \mathrm{moL}^{-1}$, the formation of the isoxazoles being exothermic by $25-30 \mathrm{kcal} \cdot \mathrm{moL}^{-1}$. Some appealing conclusions can be obtained from these energy results: (i) this 32CA reaction presents an activation enthalpy via TS-3-NO of 17.0 $\mathrm{kcal} \cdot \mathrm{moL}^{-1}$. The activation energy associated with the 32CA between the simplest NO 9 and ethylene is $15.8 \mathrm{kcal} \cdot \mathrm{moL}^{-1}$ (see Table S8 in Supplementary Material); (ii) this $32 \mathrm{CA}$ reaction is $4.6 \mathrm{kcal} \cdot \mathrm{moL}^{-1}$ more unfavourable than that involving carbenoid diphenyl NI 2a, in clear agreement with the zw-type reactivity of phenyl NO 4a; (iii) this 32CA reaction is completely regioselective, as TS-4-NO is 7.0 $\mathrm{kcal} \cdot \mathrm{moL}^{-1}$ higher in enthalpy than TS-3-NO; (iv) this 32CA reaction is highly chemoselective, as TS-1-NO is $2.3 \mathrm{kcal} \cdot \mathrm{moL}^{-1}$ higher in energy than TS-3-NO; (v) the high exothermic character of the four reaction paths makes them irreversible. Consequently, the formation of the most favourable isoxazole CA-3-NO is subject to kinetic control.

The geometries of the TSs in the gas phase and in DCM are given in Figure 3. The distances between the interacting $\mathrm{C} 1$ and $\mathrm{Cx}$ and $\mathrm{O} 3$ and $\mathrm{Cy}$ centres at the gas phase TSs are $2.185(\mathrm{C} 1-\mathrm{C} 4)$ and 2.423 (O3-C5) $\AA$ at TS-1-NO, 2.114 (O3-C4) and 2.317 (C1-C5) $\AA$ at TS-2-NO, 2.240 (C1-C8) and

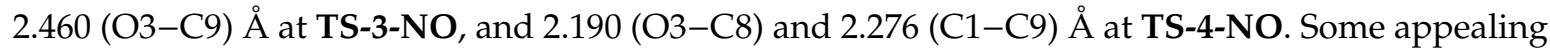
conclusions can be drawn from these geometrical parameters: (i) the more favourable regioisomeric TSs, TS-1-NO, and TS-3-NO, are more asynchronous than TS-2-NO and TS-4-NO; (ii) at the more favourable TS-1-NO and TS-3-NO, the C-C and C-O distances indicate that the formation of the $\mathrm{C}-\mathrm{C}$ single bond is more advanced than the $\mathrm{C}-\mathrm{O}$ one; (iii) similar to the 32CA reaction involving diphenyl NI 1, the C-C and C-O distances associated to the formation of the corresponding bond, $>2.1$ $\AA$, indicating that the formation of these single bonds has not started yet at any of the four TSs [21]; 
and (iv) a comparison of the geometrical parameters obtained at the B3LYP/6-31G(d) level, in the gas phase and in DCM, and those obtained at the B3LYP/6-311G(d,p) level in DCM, shows that there are no significant differences (see Figure 3).
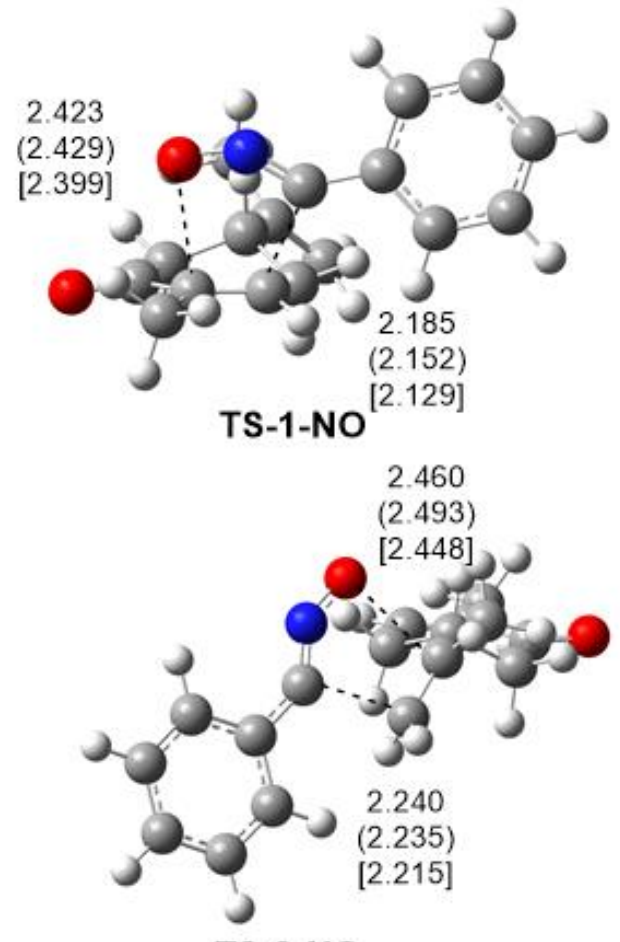

TS-3-NO
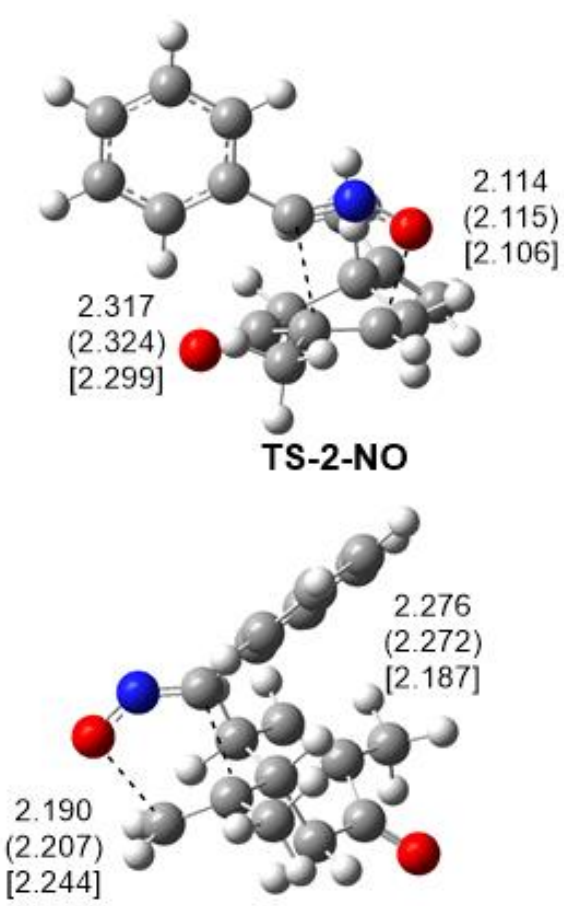

TS-4-NO

Figure 3. B3LYP/6-31G(d) optimised geometries, in gas phase and in DCM, of the TSs involved in the 32CA reaction of phenyl NO 4a with (R)-carvone 1 . Distances are given in angstroms, $\AA$. Values in DCM are given in parentheses, while the B3LYP/6-311G $(\mathrm{d}, \mathrm{p})$ values in DCM are given in brackets.

The GEDT, which fluxes from the carvone framework to the NO one, at the more favourable regioisomeric TSs is $0.00 \mathrm{e}$ at TS-1-NO and 0.05e at TS-3-NO. These negligible values indicate that this $32 \mathrm{CA}$ reaction, just as that involving NI 2a, has a non-polar character, in clear agreement with the analysis of the CDFT indices.

2.4. ELF Topological Analysis of the $C-C$ and $C-N$ Bond Formation along the Most Favourable Reaction Paths Associated with the 32CA Reaction of Diphenyl NI 2a and Phenyl NO 4a with (R)-Carvone $\mathbf{1}$

In order to characterise the formation of the two new $\mathrm{C}-\mathrm{C}$ and $\mathrm{C}-\mathrm{N}$ single bonds along the most favourable reaction paths associated with the 32CA reactions of diphenyl NI $\mathbf{2} \mathbf{a}$ and phenyl NO $4 \mathbf{a}$ with(R)-carvone 1, a topological analysis of the ELF of the structures of the intrinsic reaction coordinate (IRC) paths directly involved in the single bond formation was performed. These structures were selected by applying the Bonding Evolution Theory (BET) [35] along the corresponding gas phase B3LYP/6-31G(d) IRCs. The thorough topological analysis of the ELF is given in Sections 2 and 3, while the most relevant conclusions arising from it are given below.

2.4.1. ELF Topological Analysis of the $\mathrm{C}-\mathrm{C}$ and $\mathrm{C}-\mathrm{N}$ Bond Formation along the Most Favourable Reaction Path Associated with the 32CA Reaction of Diphenyl NI 2a with (R)-Carvone 1

Some appealing conclusions can be drawn from the topological analysis of the ELF along the 32CA reaction involving diphenyl NI 2a: (i) the moderate activation enthalpy of the non-polar 32CA reaction between diphenyl NI 2a and(R)-carvone 1, $12.4 \mathrm{kcal} \cdot \mathrm{moL}^{-1}$, can mainly be related to the depopulation of the N2-C3 bonding region of the diphenyl NI fragment, which leads to the formation 
of non-bonding electron density at the N2 nitrogen. Due to the non-polar character of the reaction, these bonding changes cannot be favoured [36]; (ii) formation of the first C3-C4 single bond takes place at S3-NI, at a C-C distance of ca. $1.98 \AA$ and with an initial population of 1.95e, by donation, in an 80:20 ratio, of the non-bonding electron density of the C3 carbenoid centre of diphenyl NI $2 a$ to a C4 pseudoradical centre created from the depopulation of the conjugated $\mathrm{C} 4-\mathrm{C} 5$ bonding region of (R)-carvone 1 along the reaction path (see Figure 4) [24]; (iii) formation of the second N1-C5 single bond takes place at the end of the reaction path at S5-NI, at an N-C distance of ca. $1.85 \AA$ and with an initial population of $1.13 \mathrm{e}$, by donation of non-bonding electron density of the N1 nitrogen to the $\mathrm{C} 5$ carbon; (iv) despite the non-polar character of the reaction, the considerably high degree of asynchronicity, ca. $82.5 \%$, computed as the separation between S3-NI and S5-NI relative to TS-1-NI in the IRC, suggests a two-stage one-step mechanism [37] (see Figure 5); (v) formation of the first C3-C4 single bond involves the most nucleophilic centre of diphenyl NI $\mathbf{2} \mathbf{a}$, which corresponds to the carbenoid C1 carbon, and the most electrophilic of (R)-carvone 1, the $\beta$-conjugated position (see section S2 in Supplementary Material) [23]. This behaviour makes it possible to explain the chemo- and regioselectivity found experimentally in this 32CA reaction [16]; and finally, (vi) the present bond formation patterns for $\mathrm{C}-\mathrm{C}$ and $\mathrm{N}-\mathrm{C}$ single bonds agree with those previously reported in $c b$-type 32CA reactions [21].

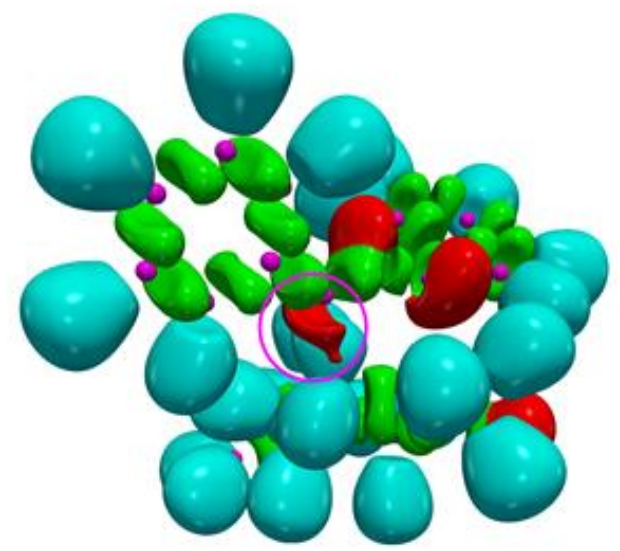

S2-NI

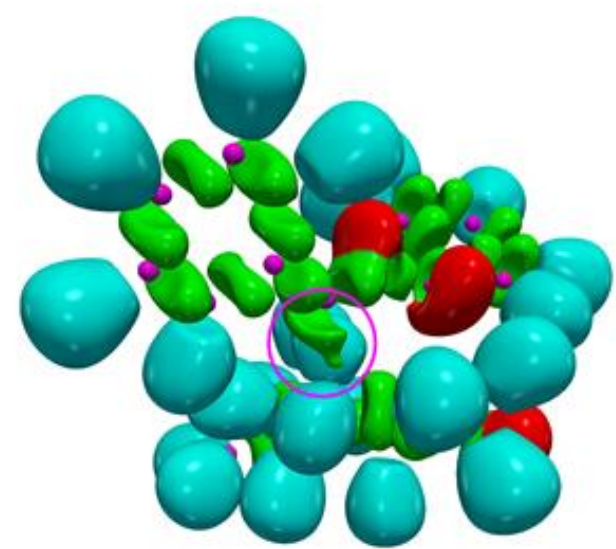

S3-NI

Figure 4. B3LYP/6-31G(d) ELF localisation domains, represented at an isosurface value of ELF = 0.75, of the structures S2-NI and S3-NI involved in the formation of the first C3-C4 single bond along the 32CA reaction between of diphenyl NI 2a and (R)-carvone 1.

2.4.2. ELF Topological Analysis of the $\mathrm{C}-\mathrm{C}$ and $\mathrm{C}-\mathrm{O}$ Bond Formation along the Most Favourable Reaction Paths Associated with the 32CA Reaction of Phenyl NO 4a with (R)-Carvone 1

Some appealing conclusions can be drawn from the topological analysis of the ELF along the 32CA reaction involving phenyl NO 4a: (i) the high activation enthalpy of the non-polar 32CA reaction between phenyl NO 4a and the isopropenyl $\mathrm{C}-\mathrm{C}$ double bond of (R)-carvone $1,17.0 \mathrm{kcal} \cdot \mathrm{moL}^{-1}$, can mainly be related to the depopulation of the N2-C3 bonding region of the NO fragment, which leads to the formation of non-bonding electron density at the two N2 nitrogen and C 3 carbon. Just as in the 32CA reaction involving diphenyl NI $\mathbf{2 a}$, the required bonding changes cannot be favoured due to the non-polar character of the reaction [36]; (ii) formation of the first $\mathrm{C} 3-\mathrm{C} 4$ single bond takes place at S3-NO, at a C-C distance of ca. $1.96 \AA$ and with an initial population of $1.33 \mathrm{e}$, by sharing part of the non-bonding electron density of the $\mathrm{C} 3$ carbon, $0.77 \mathrm{e}$, created from the depopulation of the $\mathrm{N} 2-\mathrm{C} 3$ bonding region of phenyl $\mathrm{NO} 2$, and that of the $\mathrm{C} 4$ pseudoradical centre, $0.53 \mathrm{e}$, created from the depopulation of the C4-C5 bonding region of (R)-carvone 1 in an approximate 60:40 ratio, respectively (see Figure 6) [22]; (iii) formation of the second O1-C5 single bond takes place at the end of the reaction path at S5-NO, at an O-C distance of ca. $1.80 \AA$ and with an initial population of $0.71 \mathrm{e}$, 
by donation of non-bonding electron density of the $\mathrm{O} 1$ oxygen to the small amount of non-bonding electron density created at the $\mathrm{C} 5$ carbon in an approximate 77:33 ratio; (iv) this reaction proceeds with a relatively low degree of asynchronicity, ca. 63.5\%, computed as the separation between S5-NO and S3-NO relative to TS-3-NO in the intrinsic reaction coordinate (IRC) (see Figure 7); and finally, (v) the present bond formation patterns for the $\mathrm{C}-\mathrm{C}$ and $\mathrm{O}-\mathrm{C}$ single bonds agree with those previously reported in non-polar zw-type 32CA reactions [21,22].

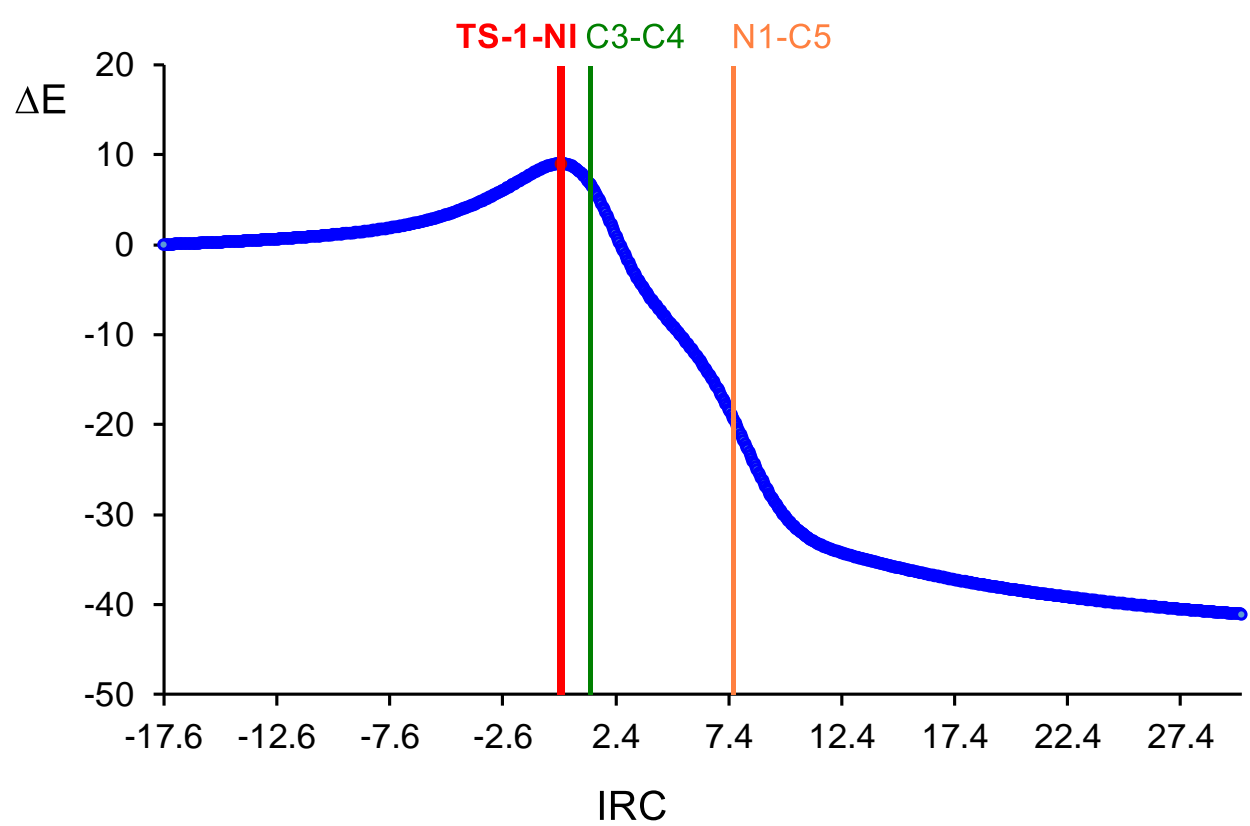

Figure 5. Gas-phase B3LYP/6-31G(d) IRC associated with the 32CA reaction between diphenyl NI 2a and (R)-carvone 1. The red line indicates the position of TS-1-NI, the green line indicates the position of the formation of the first $\mathrm{C} 3-\mathrm{C} 4$ single bond, and the orange line indicates the position of the formation of the second $\mathrm{N} 1-\mathrm{C} 5$ single bond. Relative energies $\left(\Delta \mathrm{E}\right.$, in $\left.\mathrm{kcal} \cdot \mathrm{moL}^{-1}\right)$ are given with respect to the first structure of the reaction path, S1-1-NI.

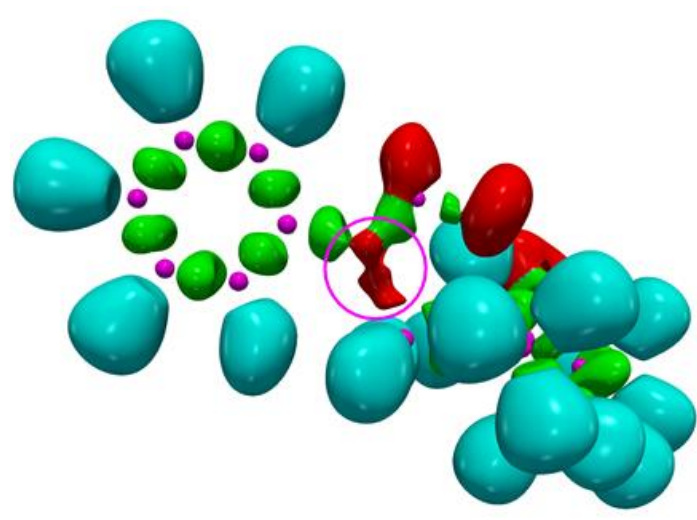

S2-NO

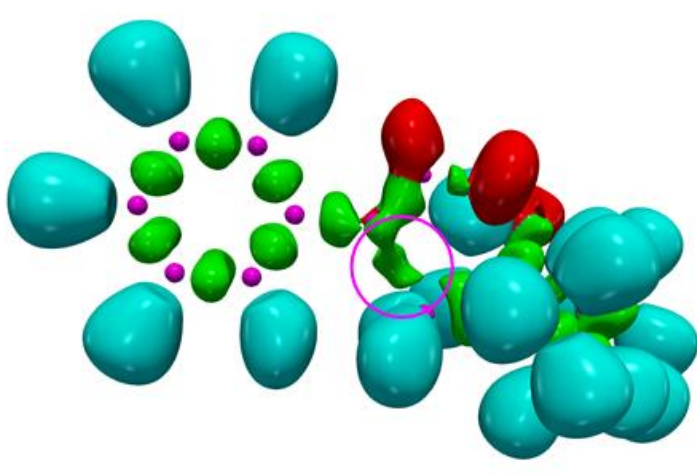

S3-NO

Figure 6. B3LYP/6-31G(d) ELF localisation domains, represented at an isosurface value of ELF $=0.75$, of the structures S2-NO and S3-NO involved in the formation of the first C3-C4 single bond along the $32 \mathrm{CA}$ reaction between of phenyl NO $4 \mathbf{a}$ and (R)-carvone $\mathbf{1}$. 


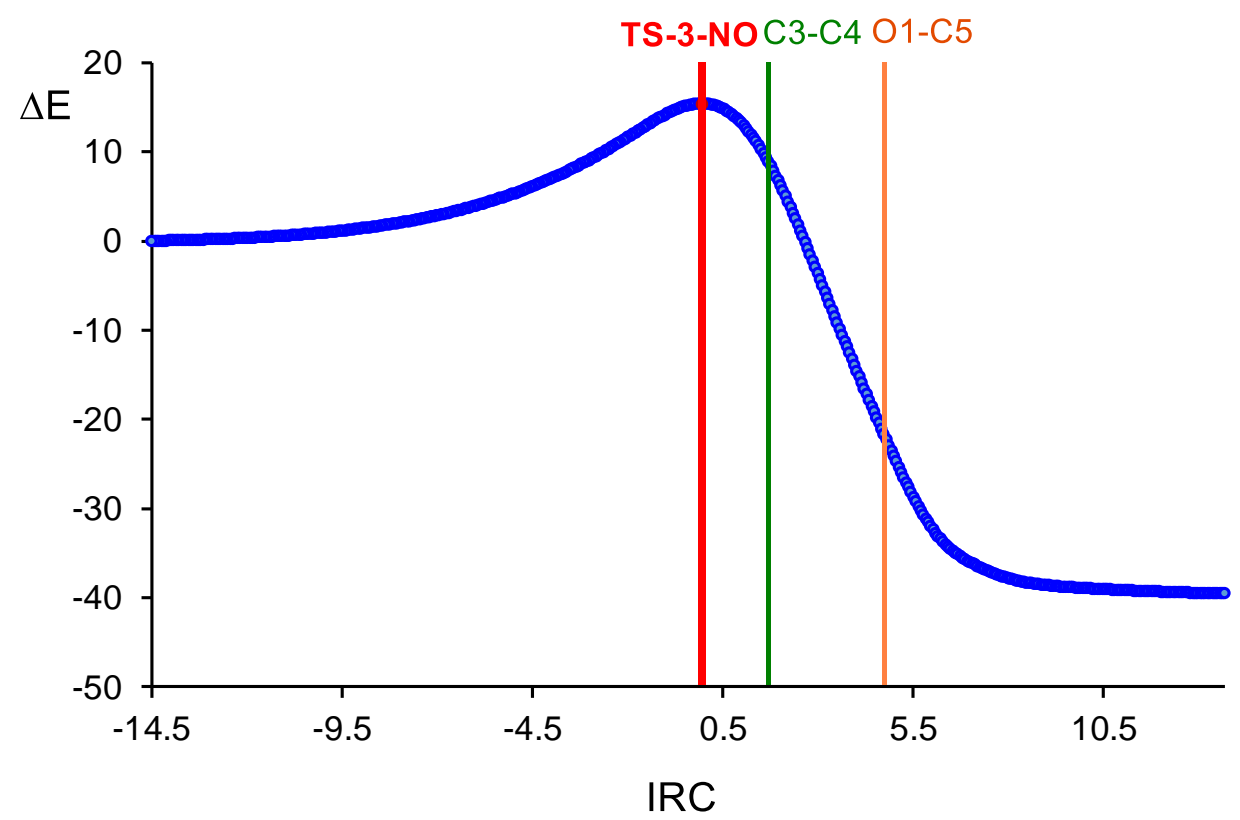

Figure 7. Gas-phase B3LYP/6-31G(d) IRC associated with the 32CA reaction between phenyl NO 4a and (R)-carvone 1. The red line indicates the position of TS-3-NO, the green line indicates the position of the formation of the first $\mathrm{C} 3-\mathrm{C} 4$ single bond, and the orange line indicates the position of the formation of the second $\mathrm{O} 1-\mathrm{C} 5$ single bond. Relative energies $\left(\Delta \mathrm{E}\right.$, in $\left.\mathrm{kcal} \cdot \mathrm{moL}^{-1}\right)$ are given with respect to the first structure of the reaction path, S1-NO.

\section{Conclusions}

The 32CA reactions of diaryl NI $\mathbf{2 a}$ and aryl NO $4 \mathbf{a}$ with $(\mathrm{R})$-carvone $\mathbf{1}$, recently studied experimentally by Ait Itto et al. [16], have been studied within the MEDT at the B3LYP/6-31G(d) and B3LYP/6-311G $(\mathrm{d}, \mathrm{p})$ computational levels, in the gas phase and in DCM.

The topological analysis of the ELF of diaryl NI 2a and aryl NO 4a allows characterising their electronic structure as carbenoid and zwitterionic TACs, respectively. Analysis of the CDFT indices indicates that the corresponding 32CA will have a low polar character given the low electrophilic character of (R)-carvone 1.

Four competitive reaction paths have been considered; two pairs of regio- and two pairs of chemoisomeric reaction paths. These 32CA reactions take place through a one-step mechanism. The activation enthalpies associated with these $32 \mathrm{CA}$ reactions are $12.4 \mathrm{kcal} \cdot \mathrm{moL}^{-1}$ (TS-1-NI) and 17.0 $\mathrm{kcal} \cdot \mathrm{moL}^{-1}$ (TS-3-NO). As expected, the $z w$-type 32CA reaction involving phenyl NO 4a presents a higher activation enthalpy than that associated to the $c b$-type 32CA reaction involving diphenyl NI 2a [21]. The two 32CA reactions are regioselective. However, while the 32CA reaction of phenyl NO 4a is highly chemoselective, preferring the attack on the isopropenyl $\mathrm{C}-\mathrm{C}$ bond of $(\mathrm{R})$-carvone 1 , that of diphenyl NI 2a presents low chemoselectivity preferring the attack to the $\alpha, \beta$-conjugated $\mathrm{C}-\mathrm{C}$ bond of $\mathbf{1}$. Although MPWB1K and M06-2X functionals correctly predict the total chemoselectivity for the 32CA reaction of diphenyl NI 2a, these functionals predict low chemoselectivity for the reaction with phenyl NO 4a. In any case, four functionals predict a change of reactivity of carbenoid diphenyl NI 2a with respect to that of zwitterionic, in complete agreement with the experimental outcomes.

ELF analysis of the formation of the two new $\mathrm{C}-\mathrm{C}$ and $\mathrm{C}-\mathrm{N}$ single bonds indicates that the $c b$-type 32CA reaction of diphenyl NI 2a begins by the $\mathrm{C}-\mathrm{C}$ bond formation between the carbenoid $\mathrm{C} 1$ carbon of NI 2a and the $\beta$-conjugated position of (R)-carvone 1 by donation [23]. On the other hand, the zw-type 32CA reaction of zwitterionic phenyl NO 4a begins by the $\mathrm{C}-\mathrm{C}$ bond formation between the $\mathrm{C} 1$ carbon of $4 \mathrm{a}$ and the methylene $\mathrm{C} 4$ carbon of the isopropenyl framework of (R)-carvone 1 , by sharing the electron density of the $\mathrm{C} 1$ and $\mathrm{C} 4$ pseudoradical centres created along the reaction path [22]. 
The present MEDT study, based on two experimental 32CA reactions [16], supports the recent classification of the 32CA reactions made by Domingo and Ríos-Gutiérrez in pdr-type, pmr-type, cb-type and zw-type reactions, and asserts MEDT, based on the analysis of molecular electron density, as an interpretative chemical theory able to explain chemical reactivity in Organic Chemistry.

\section{Computational Methods}

All stationary points were optimised using the B3LYP functional $[38,39]$ together with the 6-31G(d) and 6-311G(d,p) basis sets [40]. As this functional did not reproduce the total chemoselectivity found in the 32CA reaction of diphenyl NI 2a, the MPWB1K [41], M06-2X [42], B3LYP-D3 [43], and wB97XD [44] functionals were tested (see Supplementary Material). Although these functionals reproduced the experimental chemoselectivity of diphenyl NI 2a, all of them failed to predict the chemoselectivity found in the 32CA reaction of diphenyl phenyl NO 4a. The optimisations were carried out using the Berny analytical gradient optimisation method $[45,46]$. The stationary points were characterised by frequency computations in order to verify that TSs have one and only one imaginary frequency. The gas-phase B3LYP/6-31G(d) IRC paths [47] were traced in order to check and obtain the energy profiles connecting each TS to the two associated minima of the proposed mechanism, i.e., reactants and products, using the second-order González-Schlegel integration method [48,49]. Solvent effects of DCM were taken into account by full optimisation of the gas phase stationary points using the polarisable continuum model (PCM) $[50,51]$ in the framework of the self-consistent reaction field (SCRF) [52-54]. Values of B3LYP/6-311G(d,p) enthalpies, entropies, and Gibbs free energies in DCM were calculated with standard statistical thermodynamics at $273.15 \mathrm{~K}$ and $293.15 \mathrm{~K}$ and $1 \mathrm{~atm}$ [40].

The electronic structures of the stationary points were characterised by NPA [55,56], and by the topological analysis of the ELF [25]. CDFT reactivity indices [28,29] were computed at the B3LYP/6-31G(d) level using the equations given in reference 29. GEDT [34] was computed by the sum of the atomic charges $(\mathrm{q})$ of the atoms belonging to each framework at the TSs; GEDT $=\Sigma \mathrm{q}_{\mathrm{f}}$.

All computations were carried out with the Gaussian 16 suite of programs [57]. ELF studies were performed with the TopMod program [58], using the corresponding B3LYP/6-31G(d) monodeterminantal wavefunctions and considering the standard cubical grid of step size of 0.1 Bohr. The molecular geometries and ELF basin attractor positions were visualised using the GaussView program [59], while the ELF localisation domains were represented by means of the Paraview software at an isovalue of 0.75 a.u. $[60,61]$.

Supplementary Materials: The following are available online. Comparative analysis of the relative energies obtained using the standard B3LYP, MPWB1K, M06-2X, B3LYP-D3, and wB97XD functionals. ELF topological analysis of the $\mathrm{C}-\mathrm{C}$ and $\mathrm{C}-\mathrm{N}$ bond formation along the 32CA reactions of diphenyl NI $2 \mathbf{a}$ and phenyl NO $4 \mathbf{a}$ with (R)-carvone 1. Tables with the B3LYP/6-31G(d) total and relative energies, in the gas phase and in DCM, of the stationary points associated with the 32CA reactions of diphenyl NI 2a and phenyl NO 4a with (R)-carvone 1, as well as with the B3LYP/6-311G $(\mathrm{d}, \mathrm{p})$ thermodynamic data in DCM. Tables with the B3LYP/6-311G $(\mathrm{d}, \mathrm{p})$ thermodynamic data in DCM of the stationary points associated to the 32CA reaction of simplest NI 8 and simplest NO 9 with ethylene 6.

Author Contributions: M.R.-G. headed the subject, wrote the manuscript, and gathered the literature; L.R.D. performed the calculations and wrote the manuscript; M.E. performed the calculations and wrote the manuscript; A.O. wrote the manuscript; M.Y.A.I. wrote the manuscript. All authors have read and agreed to the published version of the manuscript.

Funding: This research has received funding from the European Union's Horizon 2020 research and innovation programme under the Marie Skłodowska-Curie grant agreement No. 84618, and the Ministry of Economy and Competitiveness (MINECO) of the Spanish Government, project CTQ2016-78669-P (AEI/FEDER, UE).

Acknowledgments: The authors acknowledge the European Commission and the Ministry of Economy and Competitiveness (MINECO) of the Spanish Government for their financial support.

Conflicts of Interest: There are no conflicts to declare. 


\section{References}

1. Al-Sehemi, A.; Bondock, S.; Ammar, Y.A. Transformations of naproxen into pyrazolecarboxamides: Search for potent anti-inflammatory, analgesic and ulcerogenic agents. Med. Chem. Res. 2014, 23, 827-838. [CrossRef]

2. Airody, V.A.; Karabasanagouda, T.; Girisha, M. Synthesis of some new pyrazolines and isoxazoles carrying 4-methylthiophenyl moiety as potential analgesic and anti-inflammatory agents. Indian J. Chem. 2009, 48B, 430-437.

3. Krishna, V.C.; Raja, S. Isoxazole-a potent pharmacophore. Int. J. Pharm. Pharm. Sci. 2017, 9, $13-24$.

4. Alegaon, S.G.; Alagawadi, K.R.; Garg, M.K.; Dushyant, K.; Vinod, D. 1,3,4-Trisubstituted pyrazole analogues as promising anti-inflammatory agents. Bioorg. Chem. 2014, 54, 51-59. [CrossRef]

5. Lincy, J.; Mathew, G. Evalutation of in vivo and in vitro anti-inflamatory activity of novel isoxazole series. Eur. Int. J. Sci. Tech. 2016, 5, 35-42.

6. Umesha, B.; Basavaraju, Y.B. Synthesis and characterization of novel benzo[d][1,3]dioxole gathered pyrazole derivatives and their antimicrobial evaluation. Med. Chem. Res. 2014, 23, 3744-3751. [CrossRef]

7. Sagar, P.; Vilasrao, K.; Ramesh, B.; Sachin, S.M.; Vijay, P. Synthesis \& Evaluation of isoxazole for their antimicrobial activity. Int. J. Comp. Adv. Pharmacol. 2017, 2, 19-26.

8. Nagamallu, R.; Srinivasan, B.; Ningappa, M.B.; Kariyappa, A.K. Synthesis of novel coumarin appended bis(formylpyrazole) derivatives: Studies on their antimicrobial and antioxidant activities. Bioorg. Med. Chem. Lett. 2016, 26, 690-694. [CrossRef]

9. Ahmad, A.; Ahmad, A.; Varsheney, H.; Rauf, A.; Rehan, M.; Subbarao, N.; Khan, A.U. Designing and synthesis of novel antimicrobial heterocyclic analogs of fatty acids. Eur. J. Med. Chem. 2013, 70, 887-900. [CrossRef]

10. Ren, J.; Wang, S.; Ni, H.; Yao, R.; Liao, C.; Ruan, B. Synthesis, Characterization and Antitumor Activity of Novel Ferrocene-Based Amides Bearing Pyrazolyl Moiety. J. Inorg. Organomet. Polym. 2015, 25, 419-426. [CrossRef]

11. Hamama, W.S.; Ibrahim, M.E.; Zoorob, H.H. Synthesis and Biological Evaluation of Some Novel Isoxazole Derivatives. J. Heterocycl. Chem. 2017, 54, 341-346. [CrossRef]

12. Fioravanti, R.; Desideri, N.; Biava, M.; Droghini, P.; Atzori, E.M.; Ibba, C.; Collu, G.; Sanna, G.; Delogu, I.; Loddo, R. N-((1,3-Diphenyl-1H-pyrazol-4-yl)methyl)anilines: A novel class of anti-RSV agents. Bioorg. Med. Chem. Lett. 2015, 25, 2401-2404. [CrossRef]

13. Li, F.; Hu, Y.; Wang, Y.; Ma, C.; Wang, J. Expeditious Lead Optimization of Isoxazole-Containing Influenza A Virus M2-S31N Inhibitors Using the Suzuki-Miyaura Cross-Coupling Reaction. J. Med. Chem. 2017, 60, 1580-1590. [CrossRef]

14. Houk, K.N.; Sims, J.; Watts, C.R.; Luskus, L.J. Origin of reactivity, regioselectivity, and periselectivity in 1,3-dipolar cycloadditions. J. Am. Chem. Soc. 1973, 95, 7301-7315. [CrossRef]

15. Rai, N.S.; Kalluraya, B.; Lingappa, B.; Shenoy, S.; Puranic, V.G. Convenient access to 1,3,4-trisubstituted pyrazoles carrying 5-nitrothiophene moiety via 1,3-dipolar cycloaddition of sydnones with acetylenic ketones and their antimicrobial evaluation. Eur. J. Med. Chem. 2008, 43, 1715-1720. [CrossRef]

16. Oubella, A.; Ait Itto, M.Y.; Auhmani, A.; Riahi, A.; Robert, A.; Daran, J.-C.; Morjani, H.; Parish, C.A.; Esseffar, M. Diastereoselective synthesis and cytotoxic evaluation of new isoxazoles and pyrazoles with monoterpenic skeleton. J. Mol. Struct. 2019, 1198, 126924. [CrossRef]

17. Ess, D.H.; Houk, K.N. Distortion/Interaction Energy Control of 1,3-Dipolar Cycloaddition Reactivity. J. Am. Chem. Soc. 2007, 129, 10646-10647. [CrossRef]

18. Ess, D.H.; Houk, K.N. Theory of 1,3-Dipolar Cycloadditions: Distortion/Interaction and Frontier Molecular Orbital Models. J. Am. Chem. Soc. 2008, 130, 10187-10198. [CrossRef]

19. Bickelhaupt, F.M. Understanding reactivity with Kohn-Sham molecular orbital theory: E2-SN2 mechanistic spectrum and other concepts. J. Comput. Chem. 1999, 20, 114-128. [CrossRef]

20. Domingo, L.R. Molecular electron density theory: A modern view of reactivity in organic chemistry. Molecules 2016, 21, 1319. [CrossRef]

21. Ríos-Gutiérrez, M.; Domingo, L.R. Unravelling the mysteries of the [3+2] cycloaddition reactions. Eur. J. Org. Chem. 2019, 267-282. [CrossRef] 
22. Domingo, L.R.; Ríos-Gutiérrez, M.; Pérez, P. A Molecular electron density theory study of the reactivity and selectivities in [3+2] cycloaddition reactions of C,N-dialkyl nitrones with ethylene derivatives. J. Org. Chem. 2018, 83, 2182-2197. [CrossRef]

23. Ríos-Gutiérrez, M.; Domingo, L.R. The Carbenoid-Type Reactivity of Simplest Nitrile Imine from a Molecular Electron Density Theory perspective. Tetrahedron 2019, 75, 1961-1967. [CrossRef]

24. Ndassa, I.M.; Adjieufack, A.I.; Ketcha, J.M.; Berski, S.; Ríos-Gutiérrez, M.; Domingo, L.R. Understanding the reactivity and regioselectivity of [3+2] cycloaddition reactions between substituted nitrile oxides and methyl acrylate. A molecular electron density theory study. Int. J. Quantum Chem. 2017, 117, 25451. [CrossRef]

25. Becke, A.D.; Edgecombe, K.E. A simple measure of electron localization in atomic and molecular-systems. J. Chem. Phys. 1990, 92, 5397-5403. [CrossRef]

26. Silvi, B.; Savin, A. Classification of chemical bonds based on topological analysis of electron localization functions. Nature 1994, 371, 683-686. [CrossRef]

27. Huisgen, R. 1,3-Dipolar Cycloadditions. Proc. Chem. Soc. 1961, 357-396.

28. Geerlings, P.; De Proft, F.; Langenaeker, W. Conceptual density functional theory. Chem. Rev. 2003, 103, 1793-1873. [CrossRef]

29. Domingo, L.R.; Ríos-Gutiérrez, M.; Pérez, P. Applications of the conceptual density functional indices to organic chemistry reactivity. Molecules 2016, 21, 748. [CrossRef]

30. Parr, R.G.; Pearson, R.G. Absolute hardness: Companion parameter to absolute electronegativity. J. Am. Chem. Soc. 1983, 105, 7512-7516. [CrossRef]

31. Parr, R.G.; Yang, W. Density Functional Theory of Atoms and Molecules; Oxford University Press: New York, NY, USA, 1989.

32. Parr, R.G.; Szentpaly, L.V.; Liu, S. Electrophilicity index. J. Am. Chem. Soc. 1999, 121, 1922-1924. [CrossRef]

33. Domingo, L.R.; Chamorro, E.; Pérez, P. Understanding the reactivity of captodative ethylenes in polar cycloaddition reactions. A theoretical study. J. Org. Chem. 2008, 73, 4615-4624. [CrossRef]

34. Domingo, L.R. A new C-C bond formation model based on the quantum chemical topology of electron density. RSC Adv. 2014, 4, 32415-32428. [CrossRef]

35. Krokidis, X.; Noury, S.; Silvi, B. Characterization of Elementary Chemical Processes by Catastrophe Theory. J. Phys. Chem. A 1997, 101, 7277-7282. [CrossRef]

36. Domingo, L.R.; Ríos-Gutiérrez, M.; Pérez, P. How does the global electron density transfer diminish activation energies in polar cycloaddition reactions? A Molecular Electron Density Theory study. Tetrahedron 2017, 73, 1718-1724. [CrossRef]

37. Domingo, L.R.; Sáez, J.A.; Zaragozá, R.J.; Arnó, M. Understanding the Participation of Quadricyclane as NucleophileinPolar $[2 \sigma+2 \sigma+2 \pi]$ Cycloadditions toward Electrophilic $\pi$ Molecules. J. Org. Chem. 2008, 73, 8791-8799. [CrossRef]

38. Becke, A.D. Density-functional thermochemistry. The role of exact Exchange. J. Chem. Phys. 1993, 98, 5648-5652. [CrossRef]

39. Lee, C.; Yang, W.; Parr, R.G. Development of the Colle-Salvetti correlation-energy formula into a functional of the electron density. Phys. Rev. B 1988, 37, 785-789. [CrossRef]

40. Hehre, M.J.; Radom, L.; Schleyer, P.v.R.; Pople, J. Ab initio Molecular Orbital Theory; Wiley: New York, NY, USA, 1986.

41. Zhao, Y.; Truhlar, D.G. Hybrid meta density functional theory methods for thermochemistry, thermochemical kinetics, and noncovalent Interactions: The MPW1B95 and MPWB1K models and comparative assessments for hydrogen bonding and van der Waals interactions. J. Phys. Chem. A 2004, 108, 6908-6918. [CrossRef]

42. Zhao, Y.; Truhlar, D.G. The M06 suite of density functionals for main group thermochemistry, thermochemical kinectics, noncovalent interactions, excited states, and transition elements: Two new functionals and systematic testing of four M06-class functionals and 12 other functionals. Theor. Chem. Acc. 2008, 120, 215-241.

43. Chai, J.-D.; Head-Gordon, M. Systematic optimization of long-range corrected hybrid density functionals. Chem. Phys. 2008, 128, 084106. [CrossRef] [PubMed]

44. Grimme, S.; Antony, J.; Ehrlich, S.; Krieg, H. A consistent and accurate ab initio parameterization of density functional dispersion correction (DFT-D) for the 94 elements H-Pu. J. Chem. Phys. 2010, 132, 154104.

45. Schlegel, H.B. Optimization of equilibrium geometries and transition structures. J. Comput. Chem. 1982, 3, 214-218. [CrossRef] 
46. Schlegel, H.B. Modern Electronic Structure Theory; Yarkony, D.R., Ed.; World Scientific Publishing: Singapore, 1994.

47. Fukui, K. Formulation of the reaction coordinate. J. Phys. Chem. 1970, 74, 4161-4163. [CrossRef]

48. González, C.; Schlegel, H.B. Reaction path following in mass-weighted internal coordinates. J. Phys. Chem. 1990, 94, 5523-5527. [CrossRef]

49. González, C.; Schlegel, H.B. Improved algorithms for reaction path following: Higher-order implicit algorithms. J. Chem. Phys. 1991, 95, 5853-5860. [CrossRef]

50. Tomasi, J.; Persico, M. Molecular interactions in solution: And overview of methods based on continuous distributions of the solvent. Chem. Rev. 1994, 94, 2027-2094. [CrossRef]

51. Simkin, B.Y.; Sheikhet, I.I. Quantum Chemical and Statistical Theory of Solutions-Computational Approach; Ellis Horwood: London, UK, 1995.

52. Cossi, M.; Barone, V.; Cammi, R.; Tomasi, J. Ab initio study of solvated molecules: A new implementation of the polarizable continuum model. Chem. Phys. Lett. 1996, 255, 327-335. [CrossRef]

53. Cances, E.; Mennucci, B.; Tomasi, J. A new integral equation formalism for the polarizable continuum model: Theoretical background and applications to isotropic and anisotropic dielectrics. J. Chem. Phys. 1997, 107, 3032-3041. [CrossRef]

54. Barone, V.; Cossi, M.; Tomasi, J. Geometry optimization of molecular structures in solution by the polarizable continuum model. J. Comput. Chem. 1998, 19, 404-417. [CrossRef]

55. Reed, A.E.; Weinstock, R.B.; Weinhold, F. Natural population analysis. J. Chem. Phys. 1985, 83, 735-746. [CrossRef]

56. Reed, A.E.; Curtiss, L.A.; Weinhold, F. Intermolecular interactions from a natural bond orbital, donor-acceptor viewpoint. Chem. Rev. 1988, 88, 899-926. [CrossRef]

57. Frisch, M.J.; Trucks, G.W.; Schlegel, H.B.; Scuseria, G.E.; Robb, M.A.; Cheeseman, J.R.; Scalmani, G.; Barone, V.; Petersson, G.A.; Nakatsuji, H.; et al. Gaussian 16, Revision A. 03; Gaussian, Inc.: Wallingford, CT, USA, 2016.

58. Noury, S.; Krokidis, X.; Fuster, F.; Silvi, B. Computational tools for the electron localization function topological analysis. Comput. Chem. 1999, 23, 597-604. [CrossRef]

59. Dennington, R.; Keith, T.A.; Millam, J.M. GaussView, Version 6.0; Semichem Inc.: Shawnee Mission, KS, USA, 2016.

60. Ahrens, J.; Geveci, B.; Law, C. ParaView: An End-User Tool for Large Data Visualization, Visualization Handbook; Elsevier: Amsterdam, The Netherlands, 2005; ISBN 978-0123875822.

61. Ayachit, U. The ParaView Guide: A Parallel Visualization Application; Kitware: Clifton Park, NY, USA, 2015; ISBN 978-1930934306.

Sample Availability: Samples of the compounds are not available from the authors.

(C) 2020 by the authors. Licensee MDPI, Basel, Switzerland. This article is an open access article distributed under the terms and conditions of the Creative Commons Attribution (CC BY) license (http://creativecommons.org/licenses/by/4.0/). 